\title{
ON THE ACTION OF THE OPTIC LOBE OF LIMULUS LONGSPINA
}

\author{
YUTAKA OOMURA AND HIROSI A. KURIYAMA* \\ Department of Physiology, Faculty of Medicine, Kyushu University, Fukuoka
}

The optic receptors in Limulus are in immediate connection with nerve fibers directly linked without having a chain of neurons to the centre. The nervous centre of the crab is found in the optic lobe of the central ganglion. This simple arrangement of visual elements can hardly fail to affect the nature of the optic lobe discharge and a knowledge of how it is affected might also give results of more general interest concerning the action of the vertebrate retina.

One of the present authors reported in a previous paper (1) on the action currents in the Limulus's optic nerve that there are no "off-responses," but two types of discharges which depend on different types of receptors, and that a temporal inhibition of spontaneous discharges is also found in response to the turning-off of light.

On the other hand, Wilska and Hartline (2) reported responses in the anterior portion of the optic lobe, to direct stimulation of the optic nerve, quite similar to the "on-responses" recorded during illumination of the eye, however in the posterior part of this region they observed responses corresponding to the "off-responses" discharging in response to the cessation of illumination of the eye and also of stimulation of the optic nerve. Therefore they concluded that these "off-responses" might be similar to those observed in the vertebrate retina (3) and that certain nerve cells might discharge impulses only in response to the cessation of preganglionic stimulation. Granit and coworkers $(4,5)$ made observations on the "off-element" in a vertebrate retina with a hope of obtaining an adequate explanation of the retinal function.

It is our intention in this paper to make clearer the nature of the optic lobe in the Limulus and gain something suggestive for the explanation of the mechanism of retinal function in vertebrates.

\section{METHOD}

A Limulus longspina caught in the Gulf of Hakata was laid on its back and fixed upon a dissection board. One pair of forelegs with a part of the carapace and fatty tissue were carefully removed to disclose the optic lobes of the central ganglion. The operation must be done quickly, because parenchymatous bleeding which does not stop during this procedure may be injurious to nervous

Received for publication December 29, 1952.

*大村 裕, 栗山 熙 
cells of the optic lobes. The oozing blood which covered the optic lobes was wiped away gently.

The optic lobe, illustrated microscopically in figure 1 , contains ganglion cells packed together by a thin connective tissue, and each ganglionic cell also encircled by a few mantle cells. The exact state of junction between the optic nerve and ganglion cell in the optic lobe is not clear.

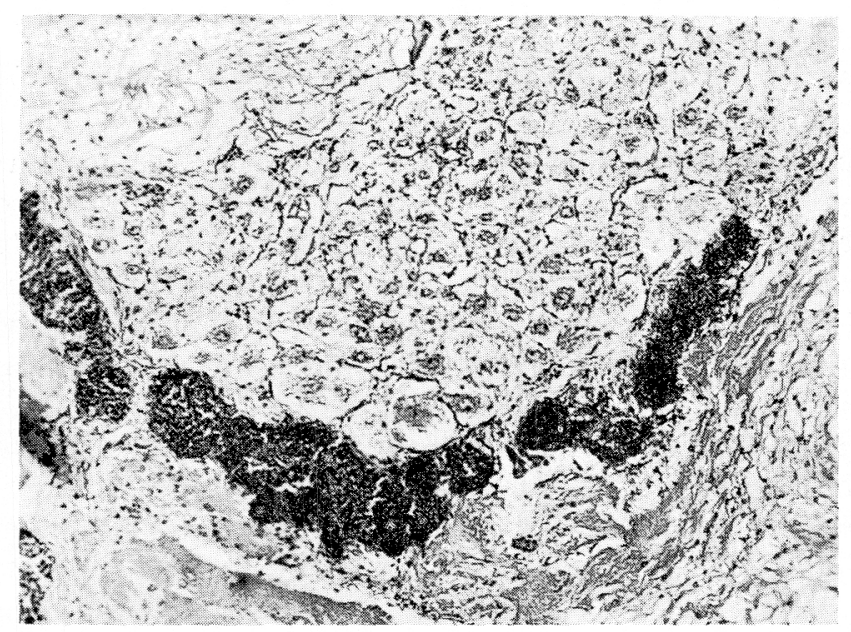

FIG. 1. Photomicrograph of a section of the optic lobe of the Limulus. Ganglion cells packed together by thin connective tissue, and each ganglion cell is also encircled by a few mantle cells.

An enamel insulated needle electrode was used. Its tip was sharpened to a size about $20 \mu$ in diameter. A three stage R-C coupled amplifier (time constant $0.05 \mathrm{sec}$.) and a cathode-ray oscilloscope with an attached camera were used for recording and observation of phenomena. The experiments were made at temperatures ranging from $25^{\circ}$ to $30^{\circ} \mathrm{C}$. in the summer.

\section{RESULTS}

Spontaneous discharge. Spontaneous discharges in the optic lobes of the Limulus are occasionally observed from various parts of the lobe.

The connection between these discharges and the activity of visual receptors is not apparent yet (fig. $2 \mathrm{~A}$ ).

Another series of spontaneous discharges are obtained from the central ganglion which seem to be of motor nature, because these discharges are found to correspond with movements of the crab, the direction of the impulses, as seen in figure $2 B$, is completely reversed.

The responses to illumination of the lateral eye are not affected by these spontaneous discharges.

Effects of illumination on the eye. When a lateral eye is exposed to light, "on" discharges appear in the optic lobe on the stimulated side with a slow frequency of $12-17$ per sec. (fig. $3 \mathrm{~A}$ ); the frequency decreases gradually with 

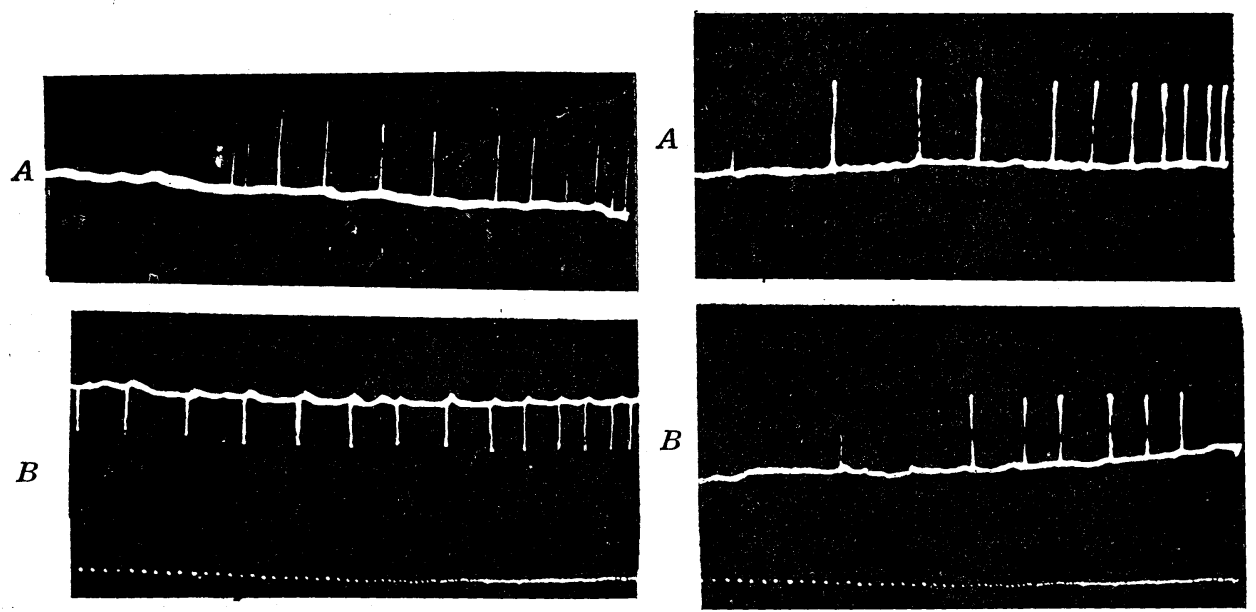

FIG. 2 (left). $A$ : Record of spontaneous discharges from a single ganglion cell in the optic lobe of the Limulus; in dark adaptation. $B$ : Record of spontaneous discharges from the central ganglion; probably of motor nature. The time is $1 / 60$ second.

FIG. 3 (right). Records of impulse discharges from a single ganglion cell in the optic lobe of the Limulus. $A:$ Response to onset of illumination of the lateral eye. $B:$ Response to cessation of illumination. The time is $1 / 60$ second; the first mark in $A$ and $B$ means the onset and the cessation of light.

time, and from the same portion we can get "off" discharges corresponding to cessation of illumination, with slower frequency of 8-12 per sec. (fig. $3 \mathrm{~B}$ ).

The portion from which "on" and "off" responses are recognized is the middle or the posterior region of the optic lobe. The "on-responses" are so labile that they are often lacking and "off" discharges are only response to illumination. This disappearance of "on-responses" may be due to bleeding rather than adaptation, because "off-response" can not usually be proved within 3 minutes after the disappearance of "on." In their experiment on the optic lobe of the Limulus, Wilska and Hartline (2) observed "on-responses" from the anterior portion of the lobe

FIG. 4. Record of discharges in a single ganglion cell the optic lobe of the Limulus. $A$ : Response to onset of illumination of the lateral eye. $B:$ Response to cessation of illumination. The time is $1 / 60$ second; the first mark in $A$ and $B$ means the onset and the cessation of light.
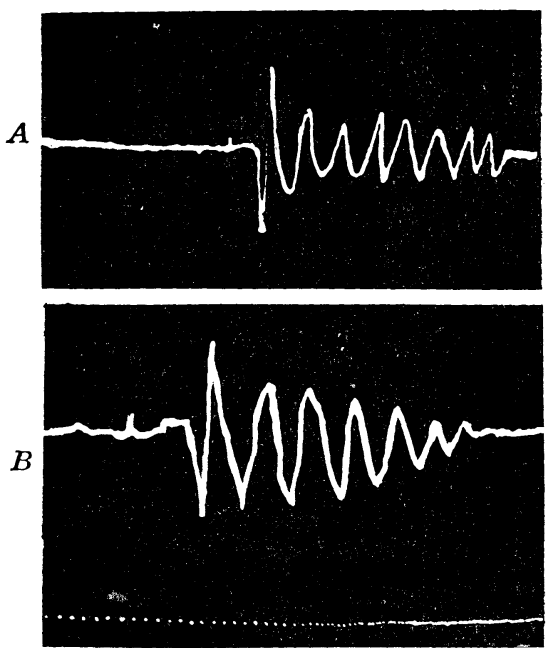
and "off-responses" from the posterior part of this region however no "onresponse" during illumination. We do not know whether they had overlooked such "on-response" from the lobe or not.

Figures $4, A$ and $B$ show oscillations in the optic lobe observed in response to illumination and cessation of light, each with proper frequency belonging to "on" and "off" responses.

On one occasion, we noticed spike discharges superimposed on the usual oscillations.

The intensity of light as a stimulus may be noticed as a factor affecting "on" oscillation. If the intensity is decreased the "on" oscillation disappears sooner.

\section{DISCUSSION}

A characteristic nature of the activity of vertebrate optic nerve is the strong discharge of impulses occurring in response to illumination and cessation of light on receptors. Phenomena taking place in the optic nerve on the way to the optic lobe in the Limulus seem to be quite similar to the former and both "on" and "off" responses may also be recognized. Moreover the "on" and "off" oscillations are proved to be from the optic lobe itself in response to exposure and cessation of light on the eye. These oscillations may be due to the activity of ganglion cells in the retina in vertebrates as Adrian and Matthews (6) and Koketsu (7) have already pointed out.

Hartline (3) observed the "off" fiber in an isolated single optic nerve of the frog, and compared it with results (2) obtained from their experiments on the optic lobe of the Limulus. He concluded that the "off-response" might be originated in the ganglionic layers of the retina in vertebrates. However, the optic lobe in the Limulus is capable of responding to both illumination and cessation of light. The mechanism of "off" response is not clear.

\section{SUMMARY}

1) Spontaneous discharges in the central ganglion are of two types; the direction of discharge of one type is similar to that of discharges in response to illumination, and discharges of the other kind originate in the motor area.

2) When the lateral eye of the crab is exposed to light action current discharges, "on-responses" are recognized in the optic lobe with a frequency about 15 per sec., and discharge "off-responses" are also revealed in response to the cessation of illumination with a frequency about 10 per sec.

The "on-responses" are very labile and liable to disapper very soon, but the "off-responses" survive usually several minutes longer than the former.

The authors acknowledge gratefully their indebtedness to prof. A. Seo and prof. N. Toida for their help in reading this paper during its preparation.

\section{REFERENCES}

1. OOMURA, Y. Jap. J. Physiol. 1953, in press. 
2. Wilska, A. And H. K. Hartline. Am. J. Physiol. 133; 491, 1941.

3. HaRTline, H. K. Am. J. Physiol. 121; 400, 1938.

4. GRANIT, R. Sensory Mechanism of Retina. London: Geoffery Cumberlege Oxford University press, 1947 .

5. Granit, R. AND K. TansleY. J. Physiol. 107: 54, 1948.

6. ADRIAN, E. D. AND R. MATTheWS. J. Physiol. 65: 273, 1928.

7. KoKetSu, K. J. Physiol. Soc. of Jap. 12: 179, 1950. 